\title{
Revisitando la escritura académica en Bibliotecología y Ciencia de la Información ¿Formalismo versus apertura?
}

\author{
Alejandro E. Parada \\ Secretario de Redacción / Información, cultura y sociedad \\ Universidad de Buenos Aires, Facultad de Filosofía y Letras, Instituto de Investigaciones \\ Bibliotecológicas-INIBI, Argentina / aparada@filo.uba.ar / https://orcid.org/oooo-0oo2-2331-442X
}

\begin{abstract}
Resumen
El presente Editorial analiza algunos aspectos poco abordados acerca de las "formas admitidas" por las revistas científicas en la producción de textos. El trabajo, circunscripto a la subjetividad de la opinión personal, no pretende poner en duda las morfologías discursivas de los artículos académicos ni las prácticas y usos de presentar las investigaciones. Por el contrario, a partir de la consolidación de dichas "formalidades", se plantea la necesidad de no ceñirse con exclusividad a esas expresiones del discurso, con el objetivo de recrear la escritura académica desde otros ángulos que han sido parcialmente abordados o no tenidos en cuenta. Se señala, entonces, la posibilidad de apelar a otras formas retóricas y discursivas no tan fuertemente estructuradas en su redacción y que pueden aportar novedosas aproximaciones a los objetos de estudio de las Humanidades y las Ciencias Sociales.
\end{abstract}

Palabras clave

Escritura

Producción de textos

Bibliotecología y Ciencia de la Información

Humanidades y Ciencias

Sociales

Aspectos teóricos

Revisiting academic writing in Librarianship and Information Science. Formalism versus openness?

\begin{abstract}
The following editorial analyzes some aspects that have been little addressed about the "accepted forms" by scientific journals in the production of texts. The present article, circumscribed to the subjectivity of personal opinion, is not intended to question the discursive morphologies of academic articles, neither the practices nor the uses of publishing researches. On the contrary, based on the consolidation of these "formalities", the need arises not to adhere exclusively to those expressions of discourse with the aim proposed to recreate academic writing from other angles that have not been considered so far. Therefore, it is suggested the possibility of appealing to other rhetorical and discursive forms not so strongly structured in their wording, which can provide novel approaches to the objects of study of the Humanities and Social Sciences.
\end{abstract}

\section{Keywords}

Text production Writing Librarianship and Information Science Humanities and Social Sciences Theoretical Aspects 
El tema de la producción escrita en Bibliotecología y Ciencia de la Información (BCI) ha sido motivo, hace pocos años, de un Editorial en Información, cultura y sociedad. En esa oportunidad las reflexiones se centraban, entre otras peculiaridades, en las limitaciones y características específicas que condicionan a nuestra profesión para generar una variedad de textos originales (Parada, 2016). No obstante, en la presente ocasión, aunque estas palabras retoman algunos conceptos allí esbozados, y utilizando como agente disparador el comentario que publicó recientemente Pedro Falcato (2019), es factible volver a aquel tópico; es decir, al mundo de la producción de textos, típico de la vida académica, para reflexionar sobre ese punto desde otra vertiente mucho más amplia y signada por lo diverso.

El discurso escrito académico, tanto en las Ciencias Sociales como en BCI, exige de ciertos presupuestos fundamentales. Requisitos de forma que deben ser respetados para que un trabajo de investigación, en el ámbito de la Universidad y de los consejos de investigación científica de cada país, sea precisamente una producción textual formal aceptada como tal por la totalidad de los integrantes de una disciplina.

Estos recursos son acordados y seguidos -también fervorosamente fomentados- casi sin cuestionamiento alguno, por dicha comunidad. Sería, en esta sumaria instancia editorial, imposible comentar el conjunto de las conductas modélicas de escritura. Como es bien sabido, y resulta ocioso su comentario, las contribuciones científicas poseen, además de una dimensión de indispensable originalidad, una estructura expositiva rigurosa y contundente, donde los temas propuestos responden a un marco teórico, a una metodología específica, a la instrumentación detallada de un asunto y su estado de la cuestión más relevante, a su discusión y, finalmente, a una serie de conclusiones generales y específicas a partir de su sustentabilidad en la bibliografía consultada y citada. Se trata de un marco fuertemente reglado a partir de la elección de su objeto de estudio hasta el último asiento pautado según las normativas bibliográficas aceptadas, aunque con variaciones entre ellas.

Es importante recordar, además, que un Editorial es una posición personal interrelacionada con proyecciones y tendencias profesionales del momento y, sobre todo, responde a la necesidad de abordar algunas líneas que escapan a los contenidos de un artículo. Un Editorial tampoco es el lineamiento incondicional del equipo de una revista, deviene, por su singularidad, en una posición individual y circunstancial; por lo tanto, al ser mudable y cambiante, su realización se rige por menores preceptos de los que presionan el contenido final de una publicación periódica. Resulta, en su significación última, opinión: una mera doxa de ese momento.

Dentro de este marco referencial y provisional es posible avanzar sobre algunos aspectos. En primer término, reflexionar sobre las estructuras formales que exige una contribución científica en el mundo de las Ciencias Sociales. Cada vez con mayor acentuación los artículos deben de estar redactados de una forma unívoca, con módulos inamovibles; en definitiva, centrados en el núcleo de una estructuración proclive a lo unidimensional. La nivelación discursiva, en su constelación de tabula rasa, determina que las producciones de distintos países y en distintas lenguas suelen parecer realizadas por una sola mano omnisciente en el reino de las revistas científicas.

Pero lo realmente alarmante y urgente es que, muchas veces, se acepta con una posición acrítica este formalismo discursivo en las Ciencias Humanas y en la BCI, de forma similar que el empleo del español neutro, solapa toda riqueza en la variación de la lengua. Esta sistematización tiende a moderar, por no decir a sustraer, toda instancia de innovación y se corre el riesgo de caer en especie de minimalismo regulado de la escritura. 
Asimismo, muchas contribuciones suelen rechazarse porque abordan asuntos que a primera vista no comprenden a intereses de la BCI y que, posteriormente, luego de un corto lapso, estos mismos temas son desarrollados por nuestro propio campo u otros de las Ciencias Humanas vinculados con la BCI, como ser la Sociología y las Ciencias Políticas. Esto se debe a que sus contenidos están presentados en un lenguaje y un orden distinto al habitual o estrictamente consentido. Por supuesto, tampoco se pretende cuestionar el arbitraje por pares, ya que eso escapa a las orientaciones de este Editorial. Lo significativo para rescatar es que existe una escritura admitida como válida y otras que permanecen fuera de esta aceptación, tanto en su forma como en su contenido. Así, toda ronda de inclusión de trabajos en una revista científica resulta una operación que responde a esta formalidad y legalidad del lenguaje académico.

Una dimensión problemática que aqueja a las redacciones de las revistas son "las modas teóricas y metodológicas" de las Ciencias Sociales. Cada período histórico, desde finales del siglo XIX y hasta los dos primeros decenios del XXI, ha tenido su tendencia marcada a fuego, una tendencia a la cual deben atenerse todas las investigadoras e investigadores. Tal el caso, para ser breves, del período que abarca desde comienzos del siglo pasado hasta la Teoría de las Prácticas y Representaciones de la Escuela de los Annales, esta última tan en boga en la actualidad. O los distintos predominios de los "giros" psicológico, existencial, lingüístico y antropológico, solo por mencionar algunos de los ascendientes que modelaron a las Humanidades y los estudios sociales. Toda producción ajena o parcialmente cuestionadora de estas orientaciones, siempre corre el riego de "quedarse en el camino" en su posible publicación. Y, en consecuencia, puede mutilar más de una carrera en la investigación. En este terreno, en la territorialidad del domino y el poder de la lucha de los lenguajes, las bajas son numerosas.

Otro tópico que implica este proceso de "aplanamiento o allanamiento discursivo" son los informes que demandan las universidades y facultades en forma persistente. Nadie cuestiona la importancia de las rendiciones de avance o finales de una investigación, que resultan indispensables como control y seguimiento. Lo que llama la atención es el culto excesivo al formato "informe". En algún momento de la trayectoria académica, se transita la incidencia de este escrito. El requerimiento de escribir dicho formato se transforma en una obligación más acuciante que la propia investigación. El informe apela a una escritura puntual, desleída, excesivamente empobrecida, sometida a procederes escrituarios prefijados y, por supuesto, a la necesidad de llenar sus contenidos sea como sea porque, en caso contrario, se corre el peligro de perder la continuidad en la proyección universitaria y naufragar en la carrera profesional.

¿Pero por qué, entonces, citar este andamiaje expositivo? Simplemente porque el informe asiduo, constante y perentorio al cual se somete la vida investigativa, conforma y manipula el modo de escribir y, sin duda, esta modelación se traslada y adapta con eficacia a los procedimientos de admisión que requieren las ediciones periódicas en Ciencias Sociales y en BCI.

Mucho se ha editado sobre "publicar o morir" (Tudela Cuenca y Aznar, 2013) y no se pretende engrosar esta abundantísima literatura. Sin embargo, existe una estrecha imbricación entre la necesidad dominante de la publicación (para mantenerse a flote en la carrera y no caer fuera del sistema) y las exigencias discursivas que adoptan una forma irrevocable.

Dentro de esta matriz funcional por reglar la escritura a las normas de la publicación científica, se corre la contingencia de dejar a un lado otras esferas de la racionalidad, bien porque escapan, en lo genérico, a las formalidades textuales, o bien porque su novedad entra en el campo de lo que sostenía Thomas S. Kuhn (1996) [1962]) en su 
obra constantemente citada La estructura de las revoluciones científicas; es decir, se precipita fuera del paradigma admitido por la totalidad de productores en las ciencias. Así, el artículo o contribución que tiene como objetivo su edición para su exposición pública, en el momento de su "puesta en texto", debe ajustarse a una plantilla o molde predeterminado y hacer de la producción un ornamento retórico. El resultado tiende a propiciar una sociedad de productores de textos que posean un perfil igualado en sus formatos. Cuando, por el contrario, cada sucesión de palabras es una forma de iluminación para comprender el pensamiento en sus complejas combinaciones (Sartre, 1964).

Además, lo expuesto trae a colación otros aspectos impensados. En la mayoría de las disciplinas de las Ciencias Sociales hay una significativa población de productores. Esto significa que las posibilidades de que aparezcan textos con discursos redactados "con múltiples alteridades" son, por transitividad poblacional, mucho mayores y, en definitiva, ayudan a modificar, a mediano o corto plazo, las maneras de expresión rígidamente admitidas.

Pero no acontece lo mismo en la Bibliotecología y Ciencia de la Información. En el área se carece de una demografía exhaustiva e intensa. Indudablemente, es un campo en crecimiento, aunque con grandes sectores vacantes y, lo aún más preocupante, con poca incidencia en la toma de decisiones que implica toda gestión de envergadura. El formalismo en la escritura de producción bibliotecológica también conlleva un incremento de la endogamia en sus investigaciones.

Es por ello que es oportuno abrir nuestra escritura a articulaciones más libres y menos configuradas. Es importante recordarlo, aunque resulte osado y temerario: los discursos académicos nivelan los modos expresivos y cohíben la posibilidad de otras creaciones disímiles a las aceptadas por todos y todas. La normalización discursiva es necesaria, pero ante el desafío de su encrucijada hay que saltar sobre el laberinto.

Deviene fundamental, pues, alentar escrituras que ayuden a ampliar la disposición concebida por los estamentos académicos; más ricas en sus formas de plantear un artículo y no caer, precisamente, en la rutina de una prosa que se acerca, con gran peligro, a los usos de los informes.

Todo esto sin perder las normativas en los procesos de edición científica. Se está reflexionando acerca de las fronteras o límites discursivos que suelen obrar como nuestras propias cadenas y sobre la aceptación, sin interrogación alguna, de cada uno de esos eslabones, algo que indudablemente hay que revisitar a través de una praxis que implique la incorporación de prácticas que atraviesen "el techo discursivo académico" en las maneras de presentar los textos.

Es un deber ineludible cuestionar las formas de escribir y leer en las Humanidades y Ciencias Sociales, ya que no existe el experimento modélico para probar nuestras afirmaciones escritas. Quizás en esta intersección se manifiesten, con su faceta subrepticia, algunos remanentes del positivismo. Es indispensable pensar que todo conocimiento y, por ende, sus modalidades de expresión y escritura en un período del pasado, fueron modernas en su tiempo y debieron de luchar por ganarse un lugar en el mundo académico. Pero el pensamiento moderno, a la corta o a la larga, se vuelve antiguo y, casi siempre, anquilosado. Ante este dilema hay que instrumentar la visibilidad de un "discurso invisible" que reclama un nuevo posicionamiento ante el dominante.

Resulta necesario expandir nuestras formas de expresar los contenidos en BCI. Esta posibilidad podría ayudar a propiciar un ambiente de renovación en la disciplina y, lo 
que es más, ganar un mayor número de investigadores para su afianzamiento y, aún un plus ultra más: dar visibilidad y contundencia a nuestras opiniones. La discusión sobre el formalismo de la escritura académica es un debate que, de llevarse a cabo entre nosotros, puede consolidar "la profesionalización de la profesión" y así arribar a otras construcciones de conocimiento.

Al comienzo de este editorial se hacía mención al texto de Falcato (2019) sobre la información y el desarrollo de sus competencias; en pocos meses, el coronavirus y la pandemia proyectaron los conceptos allí sostenidos, ya que la información y sus usos establecen dudosas e inestables trazabilidades bajo el imperio de la "infodemia". Muchos filósofos, sociólogos y pensadores han abordado la temática del tiempo, el espacio y la información en épocas de aislamiento pandémico (Pensamiento, 2020). Aquello que parecía consolidado e incuestionable en nuestras vidas, ha cambiado. La Universidad no ha estado al margen de estos acontecimientos. Las prácticas de enseñanza se han puesto en duda, por ejemplo, ante la circunstancia de pasar de las clases presenciales al dominio del aprendizaje remoto o virtual. $Y$ esto acontece, aún más, con sus discursos. Esta realidad plantea un nuevo desafío a las retóricas expresivas en el ámbito académico: el compromiso de adaptarse a otras contexturas en la producción de textos.

En definitiva, frente a la rigidez del discurso en $\mathrm{BCI}$ es importante pensar en modificar este patrón que modela en forma sustantiva a la escritura. Acaso las palabras de Aldous Huxley (1979: 139) en un magnífico y sutil ensayo hoy poco rescatado, nos brinden un escenario audaz para pensar nuestras habilidades: "Las palabras son pocas y solo pueden ordenarse en ciertos modos convencionalmente fijos; el contrapunto de acontecimientos únicos es infinitamente amplio, y su sucesión indefinidamente prolongada". 


\section{Q Referencias bibliográficas}

» Falcato, Pedro. 2019. Libertad, información y la urgencia del desarrollo de las competencias. En Información, Cultura y Sociedad. No. 41, 5-12. <https://doi. org/10.34096/ics.i41.7035>

"Huxley, Aldous. 1979. Literatura y Ciencia. Buenos Aires: Sudamericana.

» Kuhn, Thomas S. 1996 [1962]. La estructura de las revoluciones científicas. MéxiCO: FCE.

"Parada, Alejandro E. 2016. Escritura y Bibliotecología/Ciencia de la información. En Información, Cultura y Sociedad. No. 35, 5-10. <http://revistascientificas.filo.uba.ar/index.php/ICS/article/view/2881> [Consulta: 28 abril 2020].

»Pensamiento contemporáneo en tiempos de pandemias [y] La fiebre. 2020. En Medionegro. 30 de marzo de 2020. <https://www.medionegro.org/pdf-sopa-dewuhan/> [Consulta: 23 abril 2020].

"Sartre, Jean-Paul. 1964. Las palabras. Buenos Aires: Losada.

»Tudela Cuenca, Julio y Justo Aznar. 2013. ¿Publicar o morir? El fraude en la investigación y las publicaciones científicas. En Persona y bioética. Vol 17, no. 1, 12-27. <https://www.researchgate.net/publication/256706618_Publicar_o_morir_El_fraude_en_la_investigacion_y_las_publicaciones_cientificas> [Consulta: 25 abril 2020]. 